ing the sick. Scientific orientation was measured by answers to questions which showed "(a) their ultimate interests in problems of understanding basic mechanisms rather than total patient management, (b) their greater interest in literature dealing with the basic rationale underlying new therapeutic treatments rather than the effectiveness of those treatments, and (c) their self identification as researchers rather than as practising physicians. Faculty responses to each of these items were highly intercorrelated, and a composite index of orientations was constructed from them." Answers to further questions led Babbie to conclude "that science does not undermine the traditional norms of humane patient-physician relations". Looking for the basis of morality, he found religion and science were incompatible. "Moreover, Catholicism and Protestantism-hypothesized as the most involved in the freewill image-produced fewer scientific orientations than did Judaism or agnosticism."

Babbie was surprised (I would not have been) that views of moral questions were formed more by social than medical attitudes. The right to medical care, for example, was not correlated with a physician's knowledge of practical medicine. Attitudes to infanticide were most closely correlated with religion.

This is an informative book on an interesting subject, but why do social scientists, particularly American social scientists, murder the English language?

George Pickering

\section{Theology and Science}

William Dell : Master Puritan. By Eric C. Walker. Pp. $\mathrm{x}+238$. (Heffer: Cambridge, 1970.) $£ 3$.

William Dell, who receives only passing notice from historians of science, was one of the religious fanatics denounced by the two celebrated Oxford founders of the Royal Society, John Wilkins and Seth Ward. Their often cited Vindiciae Academiarum (1654) consigned Dell and other university critics to an oblivion from which they have only slowly re-emerged. Before this present book was published, the reader had access to no reliable accounts of the life and works of Dell. The patient and meticulous labours of E. C. Walker have repaired this neglect and have provided one of the best studies of puritan intellectual life in the seventeenth century.

From our point of view, Dell is more interesting and enlightened than previously recognized. His religious opinions necessitated a policy of extreme secularization of university studies.
This was a highly unpopular and somewhat paradoxical position for a clergyman head of Caius College, Cambridge. But Dell remained an uncompromising critic of his colleagues, concluding that the sciences were a theologically innocuous and economically valuable foundation for education. Equally novel was his advocation of the great extension of higher education, which should be adapted to local economic needs. Thus Dell appears as a lone proponent of scientific education in an age when even the founders of the Royal Society were complacent about the adequacy of scholastic studies. Dell was quickly ejected from his university offices, his ideas being abandoned until the nineteenth century, when it was again possible for the development of secularized and scientific university education.

\section{Webster}

\section{Energy Budget}

Productivity of Terrestrial Animals: Principles and Methods. By K. Petrusewicz and A. Macfadyen. (IBP Handbook No. 13.) Pp. xii +190. (Blackwell Scientific: Oxford and Edinburgh, 1970.) $£ 2.50$.

THIS is one of a series of handbooks prepared for the guidance of research workers in the International Biological Programme. Although the operational phase of IBP draws to a close in 1972 , studies of the productivity of terrestrial animals will continue so that the usefulness of this book will long outlive its immediate purpose.

As well as stimulating ecological research, the IBP has been valuable in promoting the international exchange of ideas and information. The present work is a good example of this ; English-speaking readers will, for example, find great value in the presentation of the ideas and methods of the outstanding Polish workers and no doubt the reverse will be equally true.

The IBP handbooks are intended to give workers in different parts of the world a methodology for research whereby their results can be compared. This is clearly difficult unless the treatise is confined to well established and thus sometimes outdated approaches. Fortunately the authors avoid the obvious pitfalls of producing a set of standard recipes and, on the contrary, the reader is left with an impression of production ecology as a field in which concepts and methods are both numerous and flexible. This is as it should be in a science still young.

The book takes one from its definitions of terms and units of measurement of metabolic balance in animal populations to a consideration of the theoretical basis and practical devices for estimating the parameters of an energy budget. Having absorbed the usually detailed and only occasionally tortuous discussion, the worker will have a good idea of the kinds of measurements required for the construction of an energy balance sheet for an animal population, and will be well aware of the problems involved in integrating the separate measurements involved. The mathematical formulations given for the calculation of production are not too daunting and appear to be workable with no more than the usual mathematical equipment of the majority of ecologists. The practical details given of the various relevant techniques such as respirometry and calorimetry will at least enable the reader to identify those most appropriate for a particular study.

No doubt the authors were faced with a difficult choice between writing a good book or a good handbook. We must be grateful that they chose the former with the result that their exposition will provide an invaluable, but not inflexible, source of fact and inspiration for many years.

\section{F. B. O'CONNOR}

\section{Igneous Africa}

Symposium on the Bushveld Igneous Complex and other Layered Intrusions. (Special Publication No. 1.) Pp. xii + 763. (Geological Society of South Africa: Johannesburg, 1970.)

THIs massive volume contains the papers contributed to a symposium on the Bushveld and other layered basic intrusions held at Pretoria in July 1969. The Geological Society of South Africa, and its editors, are to be congratulated on getting this very large volume of new work published so quickly. As the first of the society's series of special publications, it sets a very high standard. It is also a fine memorial to the late Professor Willemse, who originally planned the symposium.

The Bushveld Complex is a layered basic intrusion nearly 2,000 million years old. Covering an area of over $60,000 \mathrm{~km}^{2}$, it is the largest such intrusion in the world and it contains correspondingly unusual resources of chromite, platinum and other valuable minerals. It remains in many respects an enigma. A great deal of detailed research has been done on the complex recently, and it was timely to have the new data presented, discussed by a gathering of international experts and published.

The resulting volume serves as a complement to Wager and Brown's masterly work on Layered Igneous Rocks, by providing a mass of new 